\title{
Phaeochromocytoma in pregnancy: good luck and judgement lead to a successful outcome
}

Mie Mie Tisdale ${ }^{1}$, Alastair Mckelvey ${ }^{2}$, Neil Burgess ${ }^{3}$, Debbie O’Hare ${ }^{4}$, Francesca Swords ${ }^{1}$

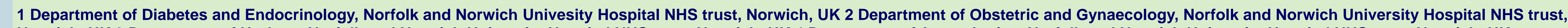

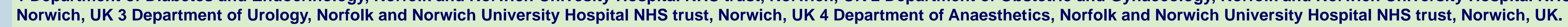

\section{Case study - History}

\section{Female, 37 years old}

Routine referral to endocrinologist with $19 \mathrm{~mm}, 40 \mathrm{HU}$ right adrenal mass found on abdominal imaging performed to investigate iron deficiency anaemia

- Highly suggestive clinical symptoms: anxiety, palpitations, breathlessness episodes, unable to sleep and exhausted for 2 months

$\circ$ No family history of MEN

Drug history: Ferrous fumarate, citalopram 30mg daily, Mefenamic acid during menstrual cycle

- Presumptive diagnosis of small phaeochromocytoma made in clinic, and patient started alpha blockade that day pending confirmatory investigations

\section{Examination Findings}

\section{Extreme anxiety}

Pulse 80 and regular

BP 130/80 mmHg

Height $169.3 \mathrm{~cm}$, Weight 69 kg, BMI 24.1

Unremarkable systemic examination

\section{Investigations}

\begin{tabular}{|l|c|c|}
\hline & Results & Reference \\
\hline $\begin{array}{l}\text { 24h Urine } \\
\text { Normetadrenaline }\end{array}$ & 3.6 & $0-3 \mathrm{umol} / 24 \mathrm{~h}$ \\
\hline 24h Urine Metadrenaline & 3.9 & $0-1.8 \mathrm{umol} / 24 \mathrm{~h}$ \\
\hline $\begin{array}{l}\text { Plasma } \\
\text { Normetanephrine }\end{array}$ & 4024 & $120-1180 \mathrm{pmol} / \mathrm{L}$ \\
\hline Plasma Metanephrine & 2205 & $80-510 \mathrm{pmol} / \mathrm{L}$ \\
\hline CT & $19 \mathrm{~mm}$ right adrenal lesion, 40 Hounsfield units \\
\hline MIBG & $\begin{array}{l}\text { Intense tracer accumulation in region of right } \\
\text { adrenal gland only }\end{array}$ \\
\hline
\end{tabular}

\section{Initial CT imaging}

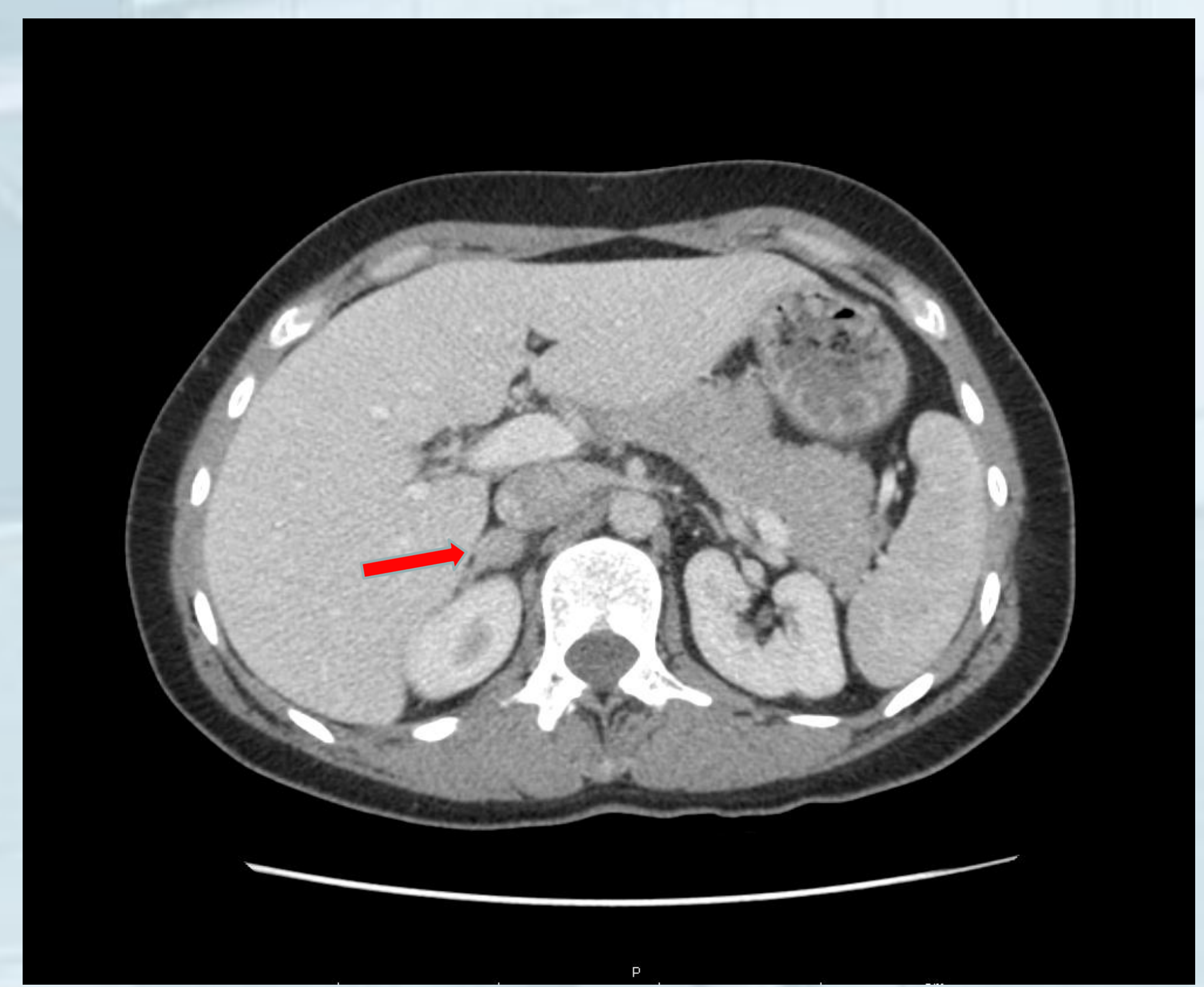

\section{MIBG scan}

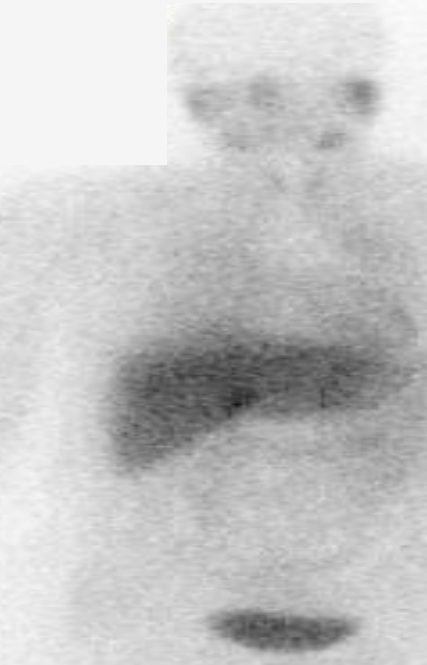

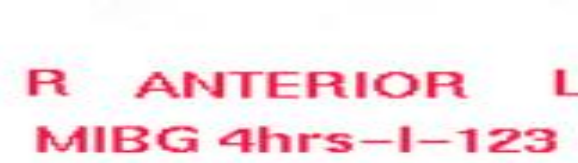

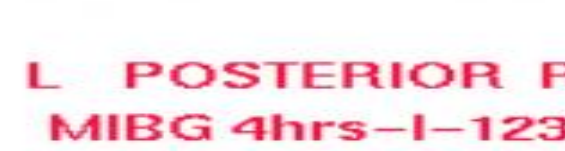

R ANTERIOR
MIBG Z1hrs-1-12

\section{Case resolution}

- The diagnosis was confirmed biochemically and alpha blockade was continued with surgery planned for 6 weeks.

- Patient then reported she was unexpectedly pregnant: LMP 2 days prior to MIBG scan.

- Close collaboration with medical obstetric, anaesthetic and surgical teams was required with full discussion of risks.

- Blockade was continued and surgery deferred to $2^{\text {nd }}$ trimester.

- Uneventful laparascopic right adrenalectomy of confirmed benign pheochromocytoma at 13 weeks gestation.

Healthy pregnancy ensued, with spontaneous vaginal delivery of $3 \mathrm{~kg}$ male infant at $\mathbf{4 0}$ weeks. Mother and son remain well.

- Phaeochromocytoma in pregnancy is very high risk for mother and child, but this case demonstrates that early diagnosis and collaborative working can lead to an excellent outcome. 